\title{
New Ethical Challenges for Today Engineering and Technology
}

\author{
Josep M. Basart \\ Engineering School \\ Universitat Autònoma de Barcelona \\ (08290) Cerdanyola del Vallès \\ Catalonia (Spain) \\ josepmaria.basart@uab.cat \\ +34935812167 \\ Mireia Farrús \\ N-RAS Research Centre \\ Universitat Pompeu Fabra \\ (08018) Barcelona \\ Catalonia (Spain) \\ mireia.farrus@upf.edu \\ +34935421118 \\ Montse Serra
}

Computer Science, Telecommunication and Multimedia Dept.

Universitat Oberta de Catalunya

(08018) Barcelona

Catalonia (Spain)

mserravi@uoc.edu

+34 933263744 


\section{Abstract}

This paper is about the intersection of three related areas: ethics, gender and the field of engineering. It is important to focus on the attitudes and values woven through this intersection because they become essential for the complete development of the moral life of the engineering profession and of the awareness of the fact that this is a profession made up of both male and female professionals. Thus, specific behaviour coming from the feminine part is necessary in order to contribute to enriching the features of the engineering profile. An approach particularly attached to feminine values, in comparison to the masculine perspective, is a sign of commitment rather than rights, a collective social group rather than the individual and of an ethic based on caring for others rather than the traditional rationalistic arguments. Because of this, the introduction of qualitative diversity within this professional field is an important fact to highlight when women contribute to the engineering community through the enrichment, expansion and transformation of the values and attitudes that are predominant in the people who work and/or study within the area of engineering and technology.

Keywords: engineering ethics, global ethics, information and communication technologies.

\section{Introduction}

We experience, day in and day out, the ways in which concerns about the role of technologies continue to grow due to the fact that we are developing a more sensitive awareness of the huge power (Weizenbaum, 1976) we are both using and deploying through the use of new Information and Communication Technologies (ICT).

Technology influences the 'ways of doing' (Mitcham, 1994) of our society, particularly when shaping its actions. Additionally, because of the spread of this technology within different scopes, the engineering professional environment is, increasingly, an environment designed and developed on a basis of technology (ICT) and is, consequently, dependent on it. We should be able to admit the existence of the two faces of engineering activity: the technological and the social. Technology influences society, but society also influences the development of that technology. An awareness of the nature of this interaction is necessary to understand how social and value issues enter into the development of technology and the intertwined paths of technological matters, legal needs and moral social issues (Adam, 2008).

For this reason, ethics takes its place in technology, contributing, substantially, towards giving it sense in human life (Arnold and Pearce, 2008). The domain of technology is recognized as a key form of human activity, and stands alongside the arts and social sciences as fundamental to human achievement and expression. Thus, the development of technological artefacts which extend and, very often, change the perception and behavioural capabilities of human beings, make available new relationships with the world in which we are living. Ethics can help us to develop sensitivities, distinct from formal knowledge, that allow engineers to improve basic social and environmental skills into their profession, and overall to 
turn engineers into committed professionals, with the willingness to involve themselves, with social awareness. So, as we can see engineering is set up from the conception of an appropriate technology in the profession, which is expressed from different points of view: intellectual, technical, ethical, aesthetic and ideological, taking into account its function and its responsibility in acting as a service to the most important customer: our society (Floridi, 2010).

From this starting point, the professional praxis and the social responsibility of engineering should aspire not only to comply with the regulations currently in force, but should aim to be the guide for the professional ethos finding inspiration in excellence, pursuing the job well done, beyond the legal minimum, future contracts and goals in the short and medium term. At this point, it is important to highlight the service that engineering has to provide to society in order to come up with its recognition for the work done and the quality achieved.

When technology and daily life are juxtaposed, as engineers we should wonder if ICT can change the quality and the shape of people's lives, thus affecting their social values (Latour, 2002; Weizenbaum, 1972). In that case, as ICT professionals, we will have to be attentive with regard to what we do when exercising engineering and the consequences that our actions have, ensuring that social well being, the common good, is not at risk.

Because of this, it is advisable to incorporate non-technical practices and contents (i.e. the ethical, legal, political, and economic issues that interweave with ICT technologies) into all engineering professional profiles. So, when taking a quick look at the present social scene in which technology plays a very important role with regard to human life, a thorough knowledge of the engineer's professional role is required. This reflection demands that the global professional features of engineering are included explicitly within the codes of ethics.

In this line, ethical issues are promoted by professional codes through professional associations and institutions such as: ACM, IEEE, ABET and NSPE. All of these are focused on the defence of the professional values of engineering such as coherence, consistency, responsibility and accountability. Thus, knowledge and practice of these responsibilities is essential to ethical thought and behaviour by ICT professionals. However, traditional codes of ethics, standards and regulations, by themselves, are not enough to guarantee moral practice (Stohl, Stohl and Popova, 2009).

At present, the development of formalized ethical standards should take into account matters such as: firstly, the new framework of the engineering profession, meaning, the context of the enormous development and global use of ICT where engineers put into practice their ethical judgments. Secondly, the current professional, as that person who has the responsibility to bear in mind the new environment brought about by the ICT society, is forced to develop new skills and abilities in order to address new social changes and needs when exercising his profession.

Taking into account these observations, then perhaps one should think about how engineering plays a central role within society and its professionals, the engineers, are one of the main actors operating as a part of a complex network of mutual relationships between many other people, organizations and 
groups. However, when combining all of these previous issues (i.e.: responsibility, ethics, technology, profession, etc.) and people's profiles (i.e.: stakeholders, customers, providers, managers, etc.), can we say that this model is complete? Meaning, does the engineer's image reflect a real model for this professional? Is an adjustment of the engineer's image needed in order to encompass male and female attributes and skills within this field? Is the present image credible that the ethical engineer is like a hero (man) who has all things under control and who has to solve all social troubles, sacrificing himself for the common good? (Basart and Serra, 2011). Probably, heterogeneous qualities from different points of view (male and female) should be demanded of all engineers in order for them to be a good professional and to satisfactorily exercise their profession. In that case the cultivation of set features of the engineer's character is accordingly required, with different perspectives coming from men and women.

Arrived at this point, heterogeneous qualities and qualitative diversity can be key points to incorporate into an engineer's profile. A clear example of this fact is the following declarations: The Earth Charter Initiative, The Universal Declaration of Human Rights and The United Nations Global Compact. These declarations have allowed us to discover what valuable elements are missed in comparison with the traditional codes of ethics, standards and regulations, taking into account the present social and environmental involvement.

The remainder of the paper has been divided into the following parts: next section 'A new vision' examines the relationship between engineering and its inherent ethical aspects taking into account the global duties and responsibilities of the engineering profession in relation to the current changing society. The third section 'New values and attitudes:' analyses the new ethical challenges of the engineering enhancing the importance of the contribution of the ethical issues coming from the feminine part. Finally, some conclusions are described in the last section.

\section{A new vision}

The word engineering relates to many different things: sciences, technologies, arts and processes are some of them. It also relates to both a profession and a business. Here we are mainly interested in these two social connections, particularly in revising certain ethical aspects of these relationships when considering engineering as a service.

\subsection{Further steps in worldwide ethics}

In the first decade of this century a new vision of our global duties and responsibilities as human beings has been consolidated worldwide. This new vision applies to all spheres of our life, public or private, and professional and business ethics are not exceptions. Four of the main characteristics of this new approach are: (1) It is centred more in communities than in individuals; (2) It puts greater emphasis on duties than on rights; (3) It integrates closer relationships between groups instead of being a defence of individualism and; (4) It is not culturally Western-centred but intercultural. Two paradigmatic examples of declarations which embrace this new vision are the United Nations Global Compact (UNGC) issued in July 2000 (UN, 2000), and the Earth Charter Initiative (ECI) issued in March, 2000 (ECI, 2000). These 
documents are of different types, but they do have in common, first, that they come from the collaboration of many people, groups and institutions from different sectors, cultures and countries and, second, that they have been formally recognized (accepted and signed) by thousands of both public and private institutions over the world. Now, we will go on with, first, some observations on how these significant declarations relate to older ethical frameworks and, second, showing why these relationships are relevant to engineering and technology given that both of them are oriented towards practice.

\subsection{Professional Codes of Ethics and Corporate Social Responsibility}

UNGC is a one-page declaration consisting of 10 principles organized in 4 sections (Human rights, Labour, Environment and, Anti-corruption). According to the overview of the declaration, "The UNGC works toward the vision of a sustainable and inclusive global economy which delivers lasting benefits to people, communities, and markets." It was a firm step towards the acknowledgment of Corporate Social Responsibility (CSR) when globalization is taken into account. More recently (June, 2011) a further development of these principles was presented by the United Nations under the title Guiding Principles on Business and Human Rights (GPBHR) (UN, 2011). Also, in October, 2011, the declaration A renewed EU strategy 2011-14 for Corporate Social Responsibility was released, with similar principles and goals, by the European Commission (EC, 2011).

Among other functions, Professional Codes of Ethics recognizes the values, goals and commitments that a community of professionals assumes with regard to society. These well-known codes have been and are still very useful to professionals because they serve to remind them of the basic principles in respect to his or her practice as, for example, an engineer, journalist or lawyer, to mention but a few.

Nevertheless, in our interconnected and interdependent world, this personal commitment, although still very valuable, is not enough to answer the complex set of responsibilities that appear around some professions. Economic globalization implies that in many cases companies operate in several regions or countries where they are, for instance, importing goods or raw materials, exporting services, designing, manufacturing, hiring workers or transferring waste products. Thus it is not just what professional do or how they do it. Considering CSR is unavoidable too that is to say, the companies, business or institutions where they are integrated, with the several roles they play, and the impacts (social and environmental) they produce.

\subsection{Human Rights and Human Duties}

The Universal Declaration of Human Rights (UDHR) was issued in December, 1948 (UN, 1948). It was a milestone in the politics of the last century and, today, in spite of its shortcomings, it continues to be probably the best agreement we have on what should be respected and promoted everywhere. However, our world has changed a lot during the 65 years which have elapsed since its announcement. Many of the current challenges and difficulties we face did not exist then, or at least they were not very pressing. For instance: economic globalization, global warming, water scarcity, environmental pollution, decline of energy supplies (oil, gas and uranium), secularization, religious fundamentalism, or technocracy, just to mention some. 
All of these circumstances are closely related to concrete responsibilities, both individual and collective, and we cannot deal with them just by appealing to abstract rights. So it seems a good idea to complement the UDHR with the other side of the picture, something like a Universal Declaration of Human Duties. Up to now, $\mathrm{ECl}$ is perhaps the most serious attempt to achieve this aim. It is a six-page declaration consisting of a preamble and 16 principles organized into 4 sections (Respect and care for the community of life, Ecological integrity, Social and economic justice and, Democracy, nonviolence and peace). Its scope is wider and more diverse than that of the UDHR. In the official text of presentation $(\mathrm{ECl}, 2012)$ it is written: "The Earth Charter is a declaration of fundamental ethical principles for building a just, sustainable and peaceful global society in the 21st century. It seeks to inspire in all people a new sense of global interdependence and shared responsibility for the well-being of the whole human family, the greater community of life, and future generations."

\subsection{Engineers and engineering activities under the new vision}

The call to complement both, human rights (UDHR) with responsibilities (ECI) and professional codes of ethics with corporate social responsibility (UNGC and GPBHR) has a clear effect on all scientific and technological activities, particularly in engineering. For this reason, we find necessary a full revision of the principles, attitudes and practices in engineering - both as a profession and as a business. This revision would involve identifying and including all the valuable elements or characteristics that have been introduced by the new vision. What follows is a tentative list including five of the main items that could be considered in a more detailed assessment:

\begin{tabular}{|l|l|l|}
\hline & $\mathrm{ECl}$ & GPBHR \\
\hline Prudence & $2 \mathrm{a}, 6 \mathrm{a}$ & $13 \mathrm{a}$ \\
\hline Active responsibility & $2 \mathrm{~b}$ & $13 \mathrm{~b}$ \\
\hline Protection and care & $2,2 \mathrm{a}, 7$ & \\
\hline Saving & $7 \mathrm{a}, 7 \mathrm{~b}$ & \\
\hline Commitment & $6 \mathrm{~b}$ & 14 \\
\hline
\end{tabular}

$\mathrm{ECl}$

2. Care for the community of life with understanding, compassion, and love.

a. Accept that with the right to own, manage, and use natural resources comes the duty to prevent environmental harm and to protect the rights of people.

b. Affirm that with increased freedom, knowledge, and power come increased responsibility to promote the common good. 
6. Prevent harm as the best method of environmental protection and, when knowledge is limited, apply a precautionary approach.

a. Take action to avoid the possibility of serious or irreversible environmental harm even when scientific knowledge is incomplete or inconclusive.

b. Place the burden of proof on those who argue that a proposed activity will not cause significant harm, and make the responsible parties liable for environmental harm.

7. Adopt patterns of production, consumption, and reproduction that safeguard Earth's regenerative capacities, human rights, and community well-being.

a. Reduce, reuse, and recycle the materials used in production and consumption systems, and ensure that residual waste can be assimilated by ecological systems.

b. Act with restraint and efficiency when using energy, and rely increasingly on renewable energy sources such as solar and wind.

GPBHR

13. The responsibility to respect human rights requires that business enterprises:

(a) Avoid causing or contributing to adverse human rights impacts through their own activities, and address such impacts when they occur;

(b) Seek to prevent or mitigate adverse human rights impacts that are directly linked to their operations, products or services by their business relationships, even if they have not contributed to those impacts.

14. The responsibility of business enterprises to respect human rights applies to all enterprises regardless of their size, sector, operational context, ownership and structure. Nevertheless, the scale and complexity of the means through which enterprises meet that responsibility may vary according to these factors and with the severity of the enterprise's adverse human rights impacts.

When reading these statements it becomes apparent that a new vocabulary is being emphasized. Words like prudence, commitment, or expressions like human rights and environment protection are not very common in technology or engineering. Furthermore, for many professionals they could sound quite odd in any engineering handbook. However, these words fit in well with the worries and needs of this century. Therefore, it seems to be appropriate that the attitudes and the frame of mind pointed out by these concepts be integrated into all spheres of engineering, step by step, but as soon as possible. Of course, paying attention to factors like efficiency, power, resistance, speed, performance or capacity, is still paramount, but today that is not enough. At least, it is not enough when we take seriously what most professional codes establish, namely that the main purpose of engineering is to enhance the safety, health and welfare of the public.

The introduction of this new vocabulary into the engineering context is also important because it helps to introduce or, at least, to remind us of, the urgency of some important questions. Whatever the final object of the engineering activity is, be it infrastructure, device, vehicle, machine, program, method or material, it is both possible and desirable to ask queries like these: Who benefits? Who or what is damaged? Who or what is protected? What new possibilities are introduced? What developments are promoted? What possibilities are excluded? What values and attitudes are involved? What are the risks? How are the risks minimized? Have worries and doubts exposed by people under risk been listened and 
responded to? Is it necessary or just feasible? Are there better choices? Is it sustainable? (Basart and Serra, 2009).

It is worth mentioning that many of these queries are closely related to some of the main focuses of interest established by the ethics of care (e.g. interdependence, vulnerability, or inequality), the new perspective on ethics founded thirty years ago by (Gilligan, 1982; Noddings, 1984). In (Pantazidou and Nair, 1999) there is a specific exploration of how the guidelines of this ethics can be successfully applied to both the teaching and the practice of engineering. However, what was considered just an interesting option in 1999 today seems to be rather more than a possibility, it has become a necessity. While the relation and the differences of this ethics with the so called feminist ethics is still an open question, there is no doubt that today engineering and technology are practiced by men and women alike and that the effects of this practice concerns all of us.

\section{New values and attitudes}

The previous questions lead undoubtedly to the rethinking of the aims and the tasks of the engineering profession. We cannot ignore how the engineering field is being influenced by the above-mentioned initiatives (ECI, GPBHR, etc.). Values like prudence, active responsibility, protection, saving and commitment, which have been traditionally attributed to women -or, more specifically, to a feminine aspect of our society - are paving the way in the engineering world.

So to speak, a traditionally-oriented engineering seems to be moving toward a more balanced one, influenced by all these new ethical challenges occurring in the current century. The means and reasons for this transition is what we will discuss in this section.

\subsection{From a masculine-oriented engineering}

We have seen that new feminine values are strongly emerging, contrasting with the fact that, for several reasons, scientific and technical careers have traditionally been a male preserve and that access by women to technical professions such as engineering is still very restricted (Hawks and Spade, 1998; Henes et al., 1995; Thom, 2001).

It is not the aim of this paper to revisit the traditional debate on the presence of women in engineering. However, in order to understand from where we are coming, we should not avoid the large number of education programs that have been designed to attract women to engineering courses with a clear objective: to balance (in numbers only) the presence of men and women in the traditionally masculine technical environments (see, for example, Heller and Martin, 1994; Salminen-Karlsson, 1999; Hermanussen and Booy, 2002).

Another related question - which is also beyond the scope of this paper - is why there is less concern about how to attract men to typically female professions. While women are gradually getting involved in 
traditionally male-dominated professions, few men are entering female-dominated professions such as nursery, school teaching, philology, secretarial, etc. In contrast, this situation is not seen as a social problem that needs a solution. Perhaps, this difference could be explained by the hero and sibyl figures introduced in Adam (2001), where the notion of the hero is explained as having been associated, over time, with the engineer man, which, in turn, has been strongly gendered to the detriment of wise women.

Several kinds of reaction to the lack of women in engineering can be encountered in the literature devoted to this area and remain alive until the present day (Baum, 1989; Hill et al., 2010; Fouad and Singh, 2011; Andrews and Clark, 2012). The motivations behind these reactions are twofold. First, they aim at removing the socio-cultural barriers that often underpin prejudices affecting women's career choices. Promoting equal opportunities for men and women - despite their biological differences - is seen as a socially and ethically positive attitude. Second, it is universally assumed that diversity is good. Having different points of view, different perspectives and different ways of working is usually seen as enriching for a working team.

Thus the fact of balancing numbers between men and women in these careers seems to ensure the universally required diversity, but such diversity becomes, in fact, a merely quantitative diversity. Is that what engineering really needs?

\subsection{Towards a more balanced engineering}

Summarizing the previous points, the main social concern related to diversity is how to attract women to those traditionally masculine professions, and how to let them do the same activities that men do. To this end, a lot of effort has been focused during recent years on the achievement of quantitative diversity. But there is a different point of view that radically changes this perspective: the questionable nature of the idea that diversity is intrinsically good was raised by Bouville (2008a). He puts on the table the truth about the universally assumed idea for which female involvement in science and engineering enables a more diverse student population and makes engineering education more successful. As he states, 'diversity is not necessary always good in and for itself'. Therefore, a qualitative diversity in the engineering world is maybe not necessarily good in and for itself.

This - sometimes unthinking - desire to be constantly surrounded by diversity should be strongly questioned. Because if diversity is good, this is may be not the best way of taking advantage of it. Based on this idea, we believe that the arguments of the Ethics of Care and the Earth Charter Initiative (among others) offer a possible pathway to follow. We must observe all these emerging feminine values and qualities and to see how they can contribute to our society. If the world ethics is walking towards this direction, we should follow it. The arguments of the Earth Charter Initiative in search of these values involving feminine and compassionate attitudes are fair enough to justify a deeper involvement of women. Not just to achieve gender diversity per se, but because such diversity can contribute to foster new values and attitudes in engineering. 
We believe that we should change the way of doing in this aspect. We should allow feminine values and attitudes to enter into the engineering world in a natural way, instead of 'forcing' women to apply for engineering careers. In other words, we should ensure a qualitative diversity, something perhaps much more rewarding that a mere quantitative diversity. We will gain a more balanced engineering, enriched by the emerging ethical values. At the same time, the presence of women will be probably increased in a very natural way, because they will see engineering as a place where they can contribute with their abilities, instead of a hostile place where they must fight to do the same as men do. Women will appreciate the importance of being there, and they will be much more involved in it.

To sum up, we believe that women can contribute to the engineering community through the enrichment, expansion and transformation of the values and attitudes that are predominant in the people who work, and/or study, within the engineering and technological area. In fact, women - like men - should contribute in those fields where they can shine. As Bouville also states in Bouville (2008b), 'They should purport to allow women to graduate in a field congruent with her abilities and desires, rather than try to draw as many of them to scientific disciplines as possible'. These desires and abilities can be in engineering or not. Undoubtedly, the presence of women in the technical fields can benefit women themselves, especially those who feel themselves underrepresented in the engineering world, but the possibilities will be greater if engineers adapt to the new feminine ethical values.

Most of all, the presence of women based on this new ethical vision will be for the benefit of engineering, and, in turn, humanity. We believe that this is the way to keep pace with the emerging ethical changes.

\section{Conclusions}

In this paper, we have reviewed some of the most relevant ethical challenges that have appeared the first decade of this century, and analysed their influence in today's engineering and technology. These new ethical changes, found in declarations like the Earth Charter Initiative and the Guiding Principles on Business and Human Rights, involve new values not usually seen beforehand in the engineering world which could be summarized as: (1) prudence, (2) active responsibility, (3) protection and care, (4) saving, and (5) commitment. Socially speaking, these values and attitudes have traditionally been associated with a feminine way of doing, which leads us to consider that new feminine values are appearing in engineering ethics.

From this point of view, we believe that these emerging values constitute a strong argument for involving more women in engineering and technical careers. Not just for balancing numbers between men and women in these fields - as has been done in the last decades - but because the engineering world is now clearly demanding their presence through the appearance of these care, protection, prudence, save and commitment values that women can contribute in a very natural way. Therefore, we also think that there is no need to force women to enter in the new engineering; if we incorporate all these demanding values in the technical fields, women will find their place, and they will be naturally 
much more involved. This change will benefit women, but undoubtedly, will also benefit engineering itself. Therefore, in the end, engineering could offer a better service to society, which is recognised as being its first commitment.

For all of this, the introduction of new moral conceptions within the engineering field related to values and attitudes will guide our future professional expectations of how men and women should work together sharing acts and talks plenty of additional engineering traits' profile such as care and relationships.

\section{References}

Adam, A., 2008. Ethics for things. Ethics and Information Technology, 7(4), 149-154.

Andrews, J., Clark, R., 2012. No one said girls could do engineering: a fresh look at an old problem, in: Conference proceedings for EE2012. Loughborough (UK): Loughborough University.

Arnold, M., Pearce, C., 2008. Is Technology Innocent? Holding Technologies to Moral Account. IEEE Technology and Society Magazine, 27(2), 44-50.

Basart, J.M., Serra, M., 2009. A Frame for Ethical Evaluation of (Information) Technologies, in: Maria Bottis (Ed.), 8th International Conference Computer Ethics: Philosophical Enquiry, Nomiki Bibliothiki Group, Athens, pp. 110-118.

Basart, J.M., Serra, M., 2011. Engineering Ethics beyond Engineer's Ethics. Science and Engineering Ethics Journal, DOI: 10.1007/s11948-011-9293-z.

Baum, E., 1989. Why So Few Women in Engineering? Engineering Education, 74(5), 556-557.

Bouville, M., 2008a. Is diversity good? Six possible conceptions of diversity and six possible answers. Science and Engineering Ethics, 14(1), 51-63.

Bouville, M. 2008b. On enrolling more female students in science and engineering. Science and Engineering Ethics, 14(2), 279-290.

EC, 2011. http://eur-lex.europa.eu/LexUriServ/LexUriServ.do?uri=com:2011:0681:fin:en:pdf. Accessed, October 31, 2013.

$\mathrm{ECl}$, 2000. http://www.earthcharterinaction.org/content/pages/read-the-charter.html. Accessed, October 31, 2013.

ECI, 2012. http://www.earthcharterinaction.org/content/pages/What-is-the-Earth-Charter\%3F.html. Accessed, October 31, 2013.

Floridi, L. (Ed.), 2010. The Cambridge Handbook of Information and Computer Ethics. Cambridge University Press, New York. 
Fouad, N.A., Singh, R., 2011. Stemming the Tide: Why Women Leave Engineering. Report. National Science Foundation \& University of Wisconsin, Milwaukee.

Gilligan, C., 1982. In a Different Voice. Psychological Theory and Women's Development, Harvard University Press, Cambridge, MA.

Hawks, B.K., Spade, J.Z., 1998. Women and Men Engineering Students: Anticipation of Family and Work Roles. Journal of Engineering Education, 87(3), 249-256.

Heller, R.S., Martin, C.D., 1994. Attracting Young Minority Women to Engineering and Science: Necessary Characteristics for Exemplary Programs. IEEE Transactions on Education, 37(1), 8-12.

Henes, R., Bland, M.M., Darby, J., McDonald, K., 1995. Improving the Academic Environment for Women Engineering Students through Faculty Workshops. Journal of Engineering Education, 84(1), 59-67.

Hermanussen, R., Booy, C., 2002. Equal Opportunity in Higher Technical Education: Past, Present and Future. International Journal of Engineering Education, 18(4), 452-457.

Hill, C., Corbett, C., St. Rose, A., 2010. Why so few? Women in Science, Technology, Engineering and Mathematics. Report of the AAUW.

Jacobs, J.E., Eccles, J.S., 1985. Gender Differences in Math Ability: The Impact of Media Reports on Parents. Educational Researcher, 14, 20-25.

Latour, B., Venn, C., 2002. Morality and Technology. The End of the Means. Theory, Culture \& Society, 19(5), 247-260.

Mitcham, C., 1994. Thinking through Technology. The University of Chicago Press, Chicago.

Noddings, N., 1984. Caring: A Feminine Approach to Ethics and Moral Education. University of California Press, Berkeley, CA.

Pantazidou, M., Nair, I., 1999. Ethic of care: Guiding principles for engineering teaching \& practice. Journal of Engineering Education, 88(2), 205-212.

Riley, D., 2013. Hidden in Plain View: Feminists Doing Engineering Ethics, Engineers Doing Feminist Ethics. Science and Engineering Ethics, 19(1), 189-206.

Salminen-Karlsson, M., 1999. Bringing Women into Computer Engineering: Curriculum Reform Processes at Two Institutes of Technology. Linköping Studies in Education and Psychology Dissertations, No. 60.

Stohl, C., Stohl M. , Popova L., 2009. A New Generation of Corporate Codes of Ethics. Journal of Business Ethics, 90(4), 607-622.

Thom, M., 2001. Balancing the Equation: Where Are Women and Girls in Science, Engineering and Technology? National Council for Research on Women, New York. 
UN, 1948. http://www.un.org/en/documents/udhr/. Accessed, October 31, 2013.

UN, 2000. http://www.unglobalcompact.org/AboutTheGC/index.html. Accessed, October 31, 2013.

UN, 2011. http://www.ohchr.org/Documents/Publications/GuidingPrinciplesBusinessHR en.pdf. Accessed, October 31, 2013.

Weizenbaum, J., 1972. The impact of the computer on society. Republished in Computers, Ethics and Social Values. Johnson and Nissenbaum (Ed.), Prentice Hall, p. 554.

Weizenbaum, J., 1976. Computer Power and Human Reason. W.H. Freeman, San Francisco, CA. 


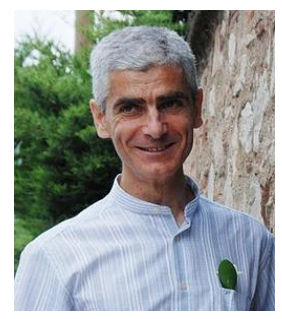

Josep M. Basart is graduated in Computer Science (1984) and in Philosophy (1998) from the Universitat Autònoma de Barcelona (UAB). He received his PhD in Computer Science (1988) by the UAB. Since 1990 he is associate professor at the Engineering School (UAB) where he has taught Engineering Ethics and several subjects in Computer Science. He has published more than 30 papers in international publications. He has collaborated in 12 funded research projects and has been reviewer for some international journals. His present areas of interest are Professional Ethics, Applied Ethics, and, Social Implications of Information and Communication Technologies.

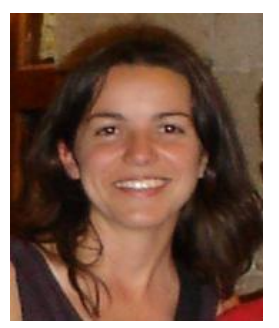

Mireia Farrús is graduated in Physics and in Linguistics from the Universitat de Barcelona. She received her PhD by the Universitat Politècnica de Catalunya, where she taught Technoethics, Engineering and Social Responsibility, and Technology and Society. She has held researcher positions in the Office of Learning Technologies at the Universitat Oberta de Catalunya, at the German Research Centre for Artificial Intelligence (Germany), Umeå Universitet (Sweden) and the National Centre for Biometric Studies at the University of Canberra (Australia). She currently works at the Universitat Pompeu Fabra, doing research in the Natural Language Processing group and teaching at the Polytechnic School.

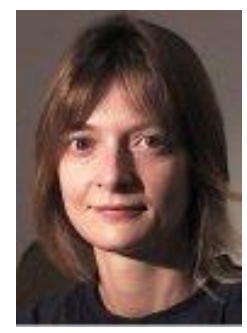

Montse Serra received a BSc in Computer Science and a PhD in Computer Science from the Universitat Autònoma de Barcelona, Spain. She has developed researcher work at Technical University of Wroclaw (Poland) in the Computer Science Faculty. She is a full-time teacher at Universitat Oberta de Catalunya, where she teaches Computer Architecture, Operating Systems and Professional Ethics. She is a part-time associate professor at Universitat Autònoma de Barcelona, where she teaches Operating Systems. Her research interests include engineering ethical issues, learning methodologies and tools for e-learning. 